\title{
User Interface Device
}

National Cancer Institute

\section{Source}

National Cancer Institute. User Interface Device. NCI Thesaurus. Code C54008.

A computer program that controls the interaction between a user and a system. 